\title{
Spatiotemporal dynamics of urban forest conversion through model urbanization in Shenzhen, China
}

\author{
CHONGFENG GONG $\dagger \ddagger$ JIQUAN CHEN $\ddagger$ and SHIXIAO YU*† \\ $\dagger$ State Key Laboratory of Biocontrol, Department of Ecology, School of Life Sciences, \\ Sun Yat-sen University, Guangzhou 510275, PR China \\ $\ddagger$ Department of Environmental Sciences, University of Toledo, Toledo, OH 43606, USA
}

(Received 12 January 2010; in final form 8 November 2010)

\begin{abstract}
In southern coastal China, Shenzhen Special Economic Zone (SEZ) was established as a model city by the government of mainland China in 1979 to demonstrate the competitive edge over Hong Kong across the straight. In less than three decades, Shenzhen has become a symbolic model city and changed from an agriculture-dominated landscape to a modern industrialization urban setting. The remote sensing approach for exploring historical land-cover change and landscape conversion paralleling a functional zone-based grid cellular analysis were used to examine the spatial-temporal changes of urban forest in Shenzhen from 1973 to 2009. Urban forest cover has been widely believed to decrease linearly and inversely to urban land regardless of spatial and temporal drivers, while our study demonstrated, in fact, that it presented as the nonlinear change with the development of the city and the transformations of underlying human demands and government's policy. Meanwhile, forest conversions over time also showed the spatial heterogeneity, which was caused by the discrepancy of urbanization range or intensity and related to both the geographical settings and socio-economic zonings of land use. In conclusion, this study revealed urbanization and its underlying biophysical and socio-economic factors could bring about the spatiotemporal dynamics of urban forest conversion (loss or gain), which affected ecosystem health and sustainable development, and reflected on the conservation management and the balance check on policy impacts on a society.
\end{abstract}

\section{Introduction}

As a major conversion from rural lands to urban lands, urbanization represents an important type of land transformation (Pickett et al. 2001) and has been regarded as one of the biggest challenges for mankind in the twenty-first century (Schweitzer 2006). In 1900, only $10 \%$ of the global population inhabited cities; however, the number has gone beyond $50 \%$ and will continuously increase over the next 50 years. Worldwide, more than $95 \%$ of the net population increase will happen in the cities of developing countries, which has been close to $80 \%$ mark in most industrialized nations today (United Nations 2006). In USA, for example, mainly due to the loss of cropland and forestland, urban area increased by 34\% between 1982 and 1997 (Alig et al. 2004). While urbanization is a worldwide phenomenon, it was notably dramatic in

*Corresponding author. Email: 1ssysx@mail.sysu.edu.cn 
China since it adopted the reform and opening-up policy in late 1978, which caused the unprecedented urban sprawl over the past two decades (Seto and Fragkias 2005). Furthermore, because more than half of its population will be urban by 2030, urban area would continue to expand at a rapid rate in the future (United Nations 2002).

Increasing population and urbanization have been responsible for major land-use and land-cover changes on this planet from local to global scales (Grimm et al. 2008). As urban areas expand, transform and envelop their surrounding land, ecosystem services at multiple spatial and temporal scales also change (Seto and Fragkias 2005). Urban forests, as the urban outdoor places with substantial amounts of trees, exist mainly in natural, semi-natural or artificial conditions (Jim and Chen 2003) and are considered as valuable green spaces for maintaining the ecological benefits and services of urban ecosystems, including maintaining biodiversity (Attwell 2000), preventing soil erosion (Dwyer et al. 1992), absorbing rainwater and pollutants (Conine et al. 2004), mitigating urban heat island effects (Yuan and Bauer 2007), improving amenity-recreation venues (Kong et al. 2007), reducing work-related stress (Gobster and Westphal 2004) and increasing property values (Geoghegan 2002). However, massive loss and fragmentation of forests within and around the urban area have become a global trend (Alig et al. 2004, MacDonald and Rudel 2005, Kupfer 2006). Efforts in protecting and managing the remnant urban forest thus are increasingly important.

Remote sensing has been considered as a powerful and effective tool for monitoring urban land-cover changes. The multispectral and multi-temporal images can provide cost-effective and valuable information for understanding urban patterns and development processes (Weng 2001). These images have been used to obtain urban land-cover characteristics and their changes over time through spectral classification (Kaufmann and Seto 2001, Hu 2007), spectral reflection model (Madhavan et al. 2001, Phinn et al. 2002) or spectral indices (Yuan and Bauer 2007). Since the Earth Resources Technology Satellite (ERTS-1) was launched in July 1972, satellite remote sensing stepped into a new age of accessible multispectral data to the public (Xie et al. 2010). Particularly, historical remotely sensed images from the Landsat program have provided objective information for the study of land-cover changes, especially on urban expansion (Seto et al. 2002), urban planning (Yu and Ng 2007), cropland and forest loss (Seto et al. 2000, Boentje and Blinnikov 2007). This is mainly due to their advantages of large area coverage, repeated viewing capability and ease of integration with a geographic information system (GIS) (Weng 2001). Furthermore, among the various sources of remote sensing satellite data, Landsat (Multi-Spectral Scanner (MSS), Thematic Mapper (TM) and Enhanced Thematic Mapper (ETM+)) images make it possible to record the land-cover changes over the past four decades (Xu et al. 2007).

The Pearl River Delta of China shares significant characteristics of typical urbanization areas, such as dense population, rapid population growth and dramatic changes in land use/land cover. For example, from 1988 to 1996 its urban area increased by more than $300 \%$ (Seto et al. 2002). Yet previous scientific investigations have focused on urban expansion, cropland loss, city planning and sustaining development (Seto et al. 2000, Kaufmann and Seto 2001, Weng 2001, Yu and Ng 2007). Located at the core region of the delta, Shenzhen Special Economic Zone (SEZ) was established as a model city by the central government of mainland China in 1979 to demonstrate the competitive edge over Hong Kong across the straight. In less than three decades, Shenzhen has become a symbolic megacity and experienced a complete 
transformation from an agriculture-dominated landscape to a modern industry urban setting.

However, sound scientific investigation on urban forest conversions within such a model city has not been made. In this study, 10 sets of land-cover maps were derived using Landsat images from 1973 to 2009 to quantify these conversions. With a particular focus on urban forest, the study objective was to explore how urbanization and underlying biophysical and socio-economic factors caused its spatial-temporal changes (forest loss or gain) by using the historical remote sensing images. We hypothesize that (1) forest cover area as the whole urbanization process should not be monotonically linear change over time and (2) the conversions of forest patches should vary in space but probably relate to some geographical settings and socio-economic zonings of the land use.

\section{Study area}

Shenzhen SEZ is located in southern China between $113^{\circ} 51^{\prime} \mathrm{E}$ to $114^{\circ} 21^{\prime} \mathrm{E}$ and $22^{\circ} 27^{\prime} \mathrm{N}$ to $22^{\circ} 39^{\prime} \mathrm{N}$, covering $395.81 \mathrm{~km}^{2}$ with four districts - Nanshan, Futian, Luohu and Yantian (figure 1). It is adjacent to the Shenzhen Bay in the southwest, the mouth of Pearl River in the west, Baoan District in the northwest, Longgang District in the northeast, Dapeng Bay in the southeast and Hong Kong in the south. The topography is characterized by open plains, rolling hills and mountains. The area has a southern subtropical climate with a mean annual temperature of $22.4^{\circ} \mathrm{C}$ and mean annual rainfall of $1933.3 \mathrm{~mm}$.

SEZ was just a small town located in the Hong Kong-mainland China border until it was declared as an SEZ in 1979. As the flagship of reform and opening-up policy, SEZ served as the regional hub of mainland China connecting to Hong Kong. Since then, SEZ witnessed the most dramatic economic development and rapid population growth. For example, the gross domestic product (GDP) increased from 0.20 billion RMB in 1979 to 495.09 billion in 2005 - an increase of nearly 2500 times. Meanwhile, the total population increased from 0.31 million to 8.28 million as a result of mass immigration (Shenzhen Statistical Bureau 2006).

\section{Methods}

\subsection{Data source and preprocessing}

Ten sets of historical Landsat images covering the SEZ were used to develop reliable land-cover maps (table 1). Due to the difference of spatial resolution among sensors, MSS images were re-sampled from 79 to $30 \mathrm{~m}$ using bilinear interpolation method for comparison with other TM or ETM images. Image preprocessing involved layer stack, images subset, radiometric calibration, geometric correction, images mosaic if necessary and images mask using the administrative boundary. All images were cloud-free and acquired during the dry season with clear weather and, therefore, the atmospheric factors could be assumed to be comparable and a correction for atmospheric parameters was not employed in the study. Geometric rectification is critical for producing spatially comparable maps along the time axis. In this study, the image of 2000 was rectified to the Universal Transverse Mercator (i.e. UTM-50N) projection based on the 1:50 000 scale topographical map. The other nine images were then calibrated with reference to the master image. More than 50 evenly distributed control points were used in each geometrical correction. These images were geometrically rectified using 


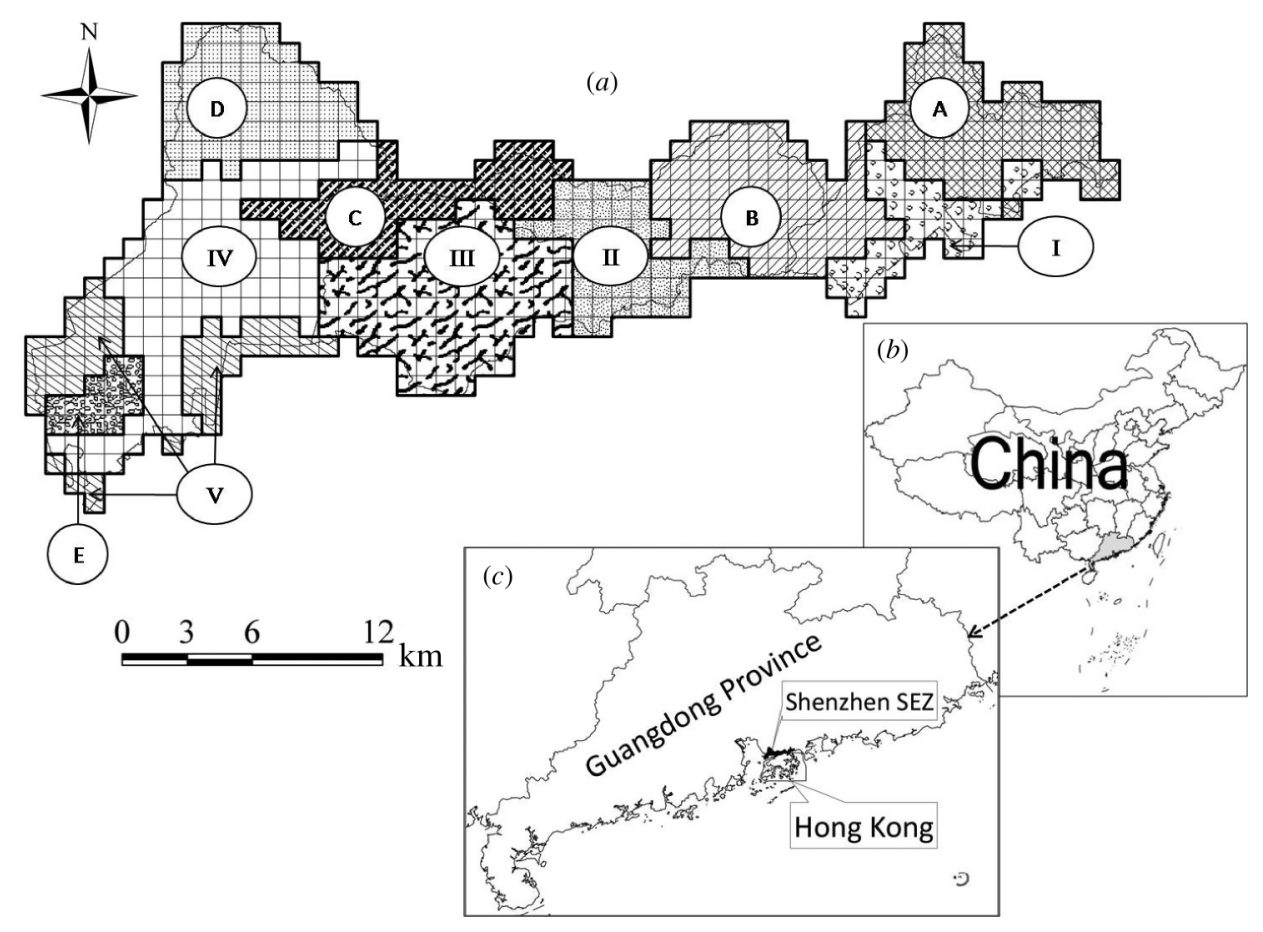

Figure 1. The functional zone-based grid cells used in this study $(a)$ and the location of Shenzhen Special Economic Zone (SEZ) $(b$ and $c)$; 569 grid cells with 900 m resolution in (a) were used to calculate conversion intensity $(\mathrm{CI})$ values using the following formula:

$$
\mathrm{CI}=\frac{\text { Annual converted area within each gird cell }}{\text { Total land cover area within each grid cell }} \times 100 \% \text {. }
$$

Notes: For detailed information see $\$ \$ 3.2$ and $3.3 ; 10$ functional zones including 5 urban zones (I-V) and 5 wildland zones (A-E) in (a) are identified by land-cover map of 2005, topography and administrative districts; the descriptions of these functional zones are listed in table 2.

a second-order polynomial geometrical model and re-sampled by a nearest neighbour algorithm. All of the root mean square errors (RMSEs) are less than one-third of a pixel and reported in table 1 .

This study adopted an integrated land-cover maps retrieval, landscape change detection and landscape conversion intensity (CI) analysis to detect the spatialtemporal dynamics of urban land and urban forest cover for the study area. The image processing procedures included (1) preprocessing, (2) land-cover maps retrieval, (3) landscape conversion detection, (4) grid cellular-based CI quantification and (5) functional zone-based analysis. All processes were performed using ERDAS IMAGINE and ArcGIS software.

\subsection{Land-cover changes}

An integrated classification method was used to derive the land-cover maps (figure 2). First, a preliminary analysis of the images based on an unsupervised classification approach was performed to identify spectral clusters corresponding to 
Table 1. Descriptions of Landsat images used in this study.

\begin{tabular}{llcccr}
\hline & \multicolumn{1}{c}{$\begin{array}{c}\text { WRS path/row, } \\
\text { sensor and } \\
\text { Year }\end{array}$} & $\begin{array}{c}\text { Resolution } \\
(\mathrm{m})\end{array}$ & $\begin{array}{c}\text { Geometric } \\
\text { registration } \\
\text { RMSE }\end{array}$ & $\begin{array}{c}\text { Overall } \\
\text { accuracy } \\
(\%)\end{array}$ & Kappa \\
\hline 1973 & $\begin{array}{l}\text { p131r44_MSS_19731225 } \\
\text { p130r44_MSS_19731031* }\end{array}$ & 79 & \pm 0.290 & 75.19 & 0.71 \\
1979 & $\begin{array}{l}\text { p131r44_MSS_19791019 } \\
\text { p130r44_MSS_19790930* }\end{array}$ & 79 & \pm 0.297 & 83.76 & 0.80 \\
1986 & p121r44_TM5_19861224 & 30 & \pm 0.278 & 87.64 & 0.85 \\
& p122r44_TM5_19870106* & & & & \\
1991 & p121r44_TM5_19911009 & 30 & \pm 0.262 & 77.12 & 0.74 \\
& p122r44_TM5_19901013* & & & & \\
1995 & p122r44_TM5_19951230 & 30 & \pm 0.241 & 86.50 & 0.82 \\
1998 & p122r44_TM5_19981222 & 30 & \pm 0.236 & 90.14 & 0.88 \\
2000 & p122r44_TM7_20001101 & 30 & Master image & 89.67 & 0.86 \\
2003 & p122r44_TM7_20030110 & 30 & \pm 0.235 & 90.82 & 0.89 \\
2005 & p122r44_TM5_20051123 & 30 & \pm 0.238 & 91.00 & 0.89 \\
2009 & p122r44_TM5_20090102 & 30 & \pm 0.291 & 92.00 & 0.90 \\
\hline
\end{tabular}

Notes: RMSE, root mean square error; WRS, Worldwide Reference System.

*As ancillary images to mosaic with the primary image for covering the entire study area.

the vegetation-impervious-soil (V-I-S) composition model (Ridd 1995, Madhavan et al. 2001, Phinn et al. 2002). However, due to the limit of spatial and spectral resolution of Landsat sensor as well as the complex urban context, the spectral confusion was noticeable, which meant several cover classes had similar spectral response. Therefore, visual (or manual) interpretation was employed in the study to allow a comprehension of spatial and spectral contents with the use of human wisdom and experience. At present, visual interpretation could be incorporated effectively into a digital classification procedure by on-screen digitizing and other relevant GIS tools such as overlaying and recoding. Consequently, four components of the urban surface features were identified unambiguously, which consisted of urban land, bare land, water area and vegetation. With the aim of extracting forest from the vegetation, three subtypes including grassland, shrubland and forest were further classified based on the normalized difference vegetation index (NDVI) values by iterative self-organizing data analysis (ISODATA) technique (ERDAS 2003, Stow et al. 2003, Hu 2007). To reduce the boundary errors at class boundaries and the noises of anomalous pixels within classes, usually in the form of 'salt and pepper', a contextual post-classification procedure was used to remove small areas and replace with class values of their surroundings. This procedure involved two stages: (1) identifying minimal area (two pixels used in this study) and their subsequent declassification and (2) re-labelling of declassified areas on the basis of their surrounding pixels.

Accuracy assessment is critical for image classification, whereas it would be difficult to carry out such assessment for the historical images. In this study, the error matrix analysis, a discrete multivariate technique (Congalton 1991) which could produce overall accuracy and kappa statistics, was employed to perform this procedure. For an unbiased assessment, the stratified random sample strategy was used to select 25 samples for each class totalling 150 samples per image. To substantiate the classification of the 2005 image, the data of fieldwork with plot survey during the corresponding period were used as ground truth. To assess the classification accuracy 

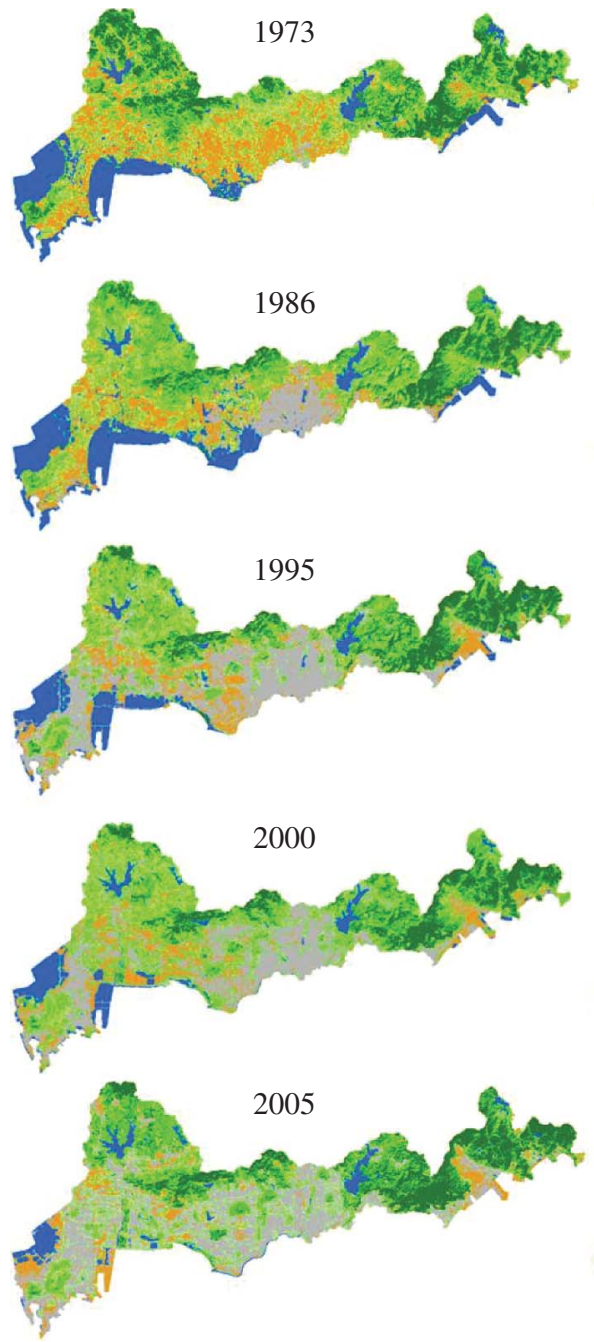
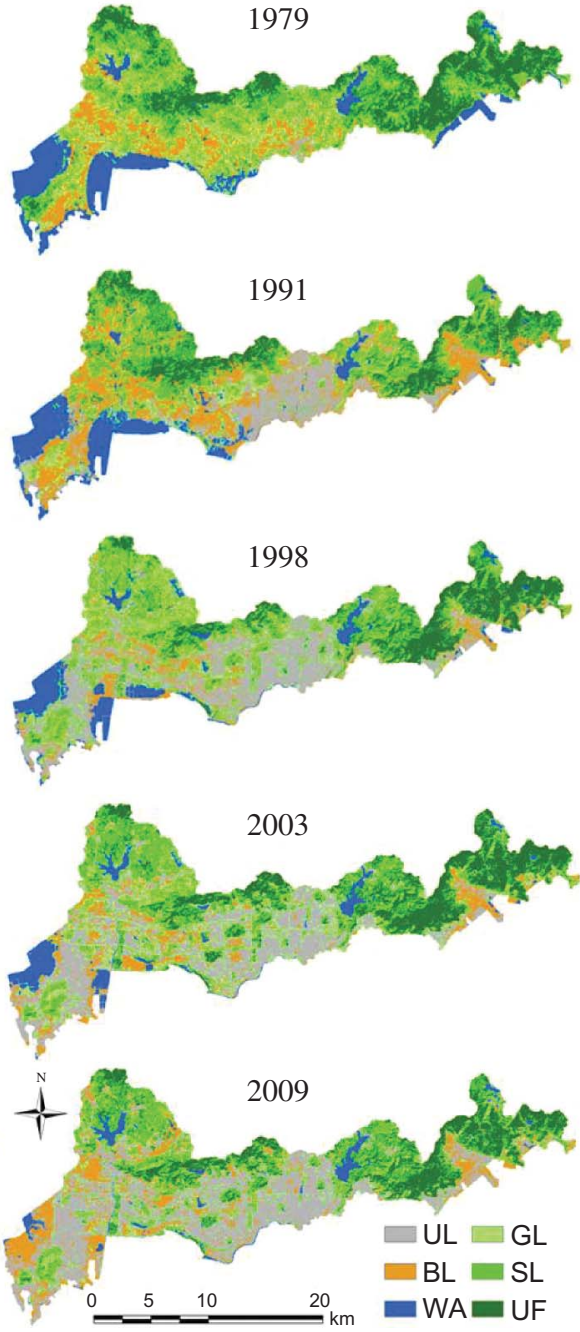

Figure 2. Land-cover maps of Shenzhen 1973 through 2009 retrieved from 10 sets of Landsat imagery.

Note: UL, Urban land; BL, bare land; WA, water area; GL, grassland; SL, shrubland; UF, urban forest.

of historical images (i.e. other eight images), the following two methods were used: (1) reference high-resolution images within the corresponding year were used to verify the historical land-cover types. For example, the panchromatic and multispectral SPOT5 images were used for 2003 image and aerial photos for 2000 image. (2) A variety of historical documents including city maps, topographic maps and yearbooks were collected and analysed to provide verification of past land-cover types. The results of the accuracy assessments are reported in table 1, including overall accuracies and Kappa statistics. Generally, the accuracy of the classifications could be satisfactory, with the lowest values for the 1973 image (an overall accuracy of 75.19\% and a Kappa index of 0.71). Furthermore, for the focused classes (i.e. urban land and urban forest), 

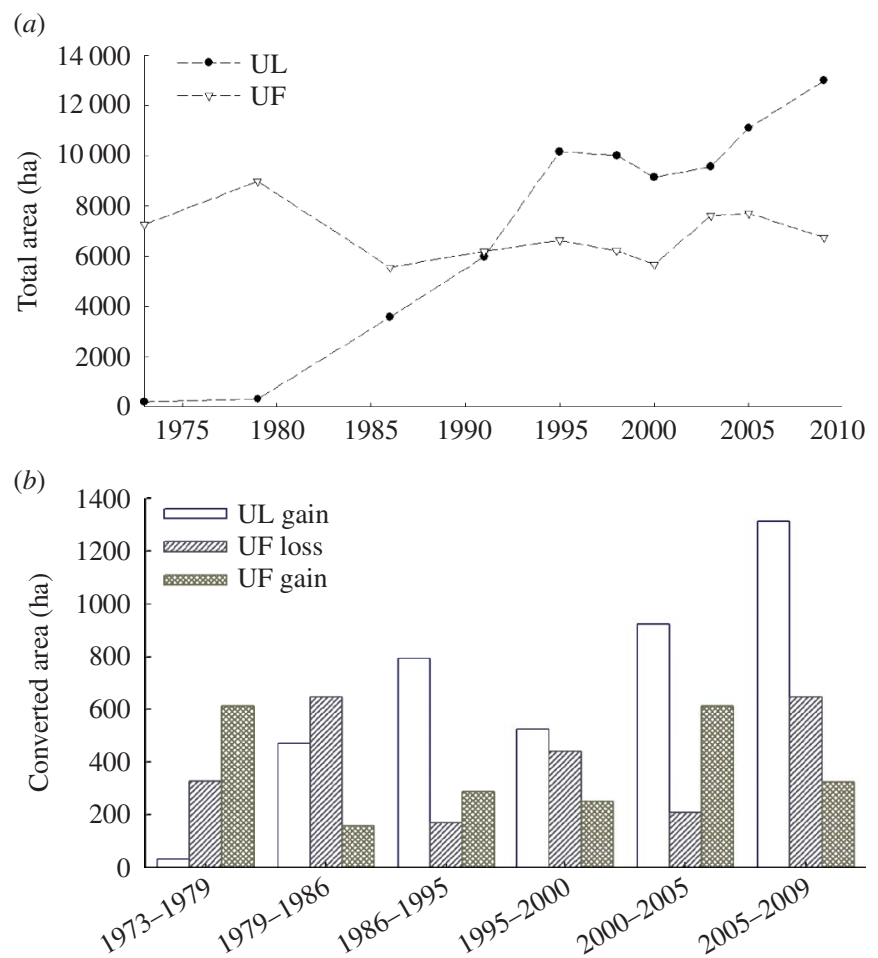

Figure 3. The total land-cover area changes $(a)$ of UL and UF as well as their converted loss or gain area $(b)$ along the time axis. (The converted area has been standardized to annual amount.) Note: UL, Urban land; UF, urban forest.

all images in terms of producer's accuracy ranged from 84 to $100 \%$, while in terms of user's accuracy, all were over $71 \%$.

In order to evaluate the changes of urban land and forest cover over time, the total area change trends were first examined in figure 3(a). Based on their change trends, six study stages were recognized: 1973-1979 (the pre-urban stage), 1979-1986 (the initial stage), 1986-1995 (the accelerated stage), 1995-2000 (the relatively steady stage I), 2000-2005 (the relatively steady stage II) and 2005-2009 (the latest stage). The land-use conversion matrices based on pixel-to-pixel comparison were constructed to calculate converted areas of urban land and urban forest using the two adjacent maps of each stage (Ridd and Liu 1998, Yang 2002). Because of the unequal intervals among different stages, the converted area was standardized to an annual amount for the comparability:

$$
\begin{gathered}
\mathrm{ACA}_{\text {loss }}=\frac{\mathrm{LCA}_{i}-\mathrm{LCA}_{i+n}}{n} \times 100 \% \\
\mathrm{ACA}_{\text {gain }}=\frac{\mathrm{LCA}_{i+n}-\mathrm{LCA}_{i}}{n} \times 100 \%
\end{gathered}
$$


where $\mathrm{ACA}_{\text {loss }}$ and $\mathrm{ACA}_{\text {gain }}$ are annual conversion area to (i.e. conversion loss) or from (i.e. conversion gain) other classes; $n$ is the interval of study stages (in years); $\mathrm{LCA}_{i}$ and $\mathrm{LCA}_{i+n}$ are the land-cover area at year $i$ and $i+n$, respectively. The results of conversion loss or gain at urban land and forest are illustrated in figure $3(b)$. The conversion loss or gain of forest cover with other different classes was also calculated to identify the source of forest gain or the sink of forest loss. Finally, two adjacent maps of each stage were combined to produce the conversion maps by image calculator to examine the specific locations of loss or gain.

\subsection{Functional zone-based landscape conversion}

Since the introduction of 'gradient paradigm' in urban ecological research (McDonnell and Pickett 1990), studies of landscape change along an urban-to-rural gradient have been focused on the identification of urban texture - whether urban landscapes have unique 'spatial signatures'. However, urban landscapes are dynamic and continuously changing as the city growth (Weng 2007) and thus it is difficult to completely detect the changes of time-series conversion maps along the single gradient. Accordingly, a functional zone-based grid cellular analysis was conducted in this study which was also largely because Shenzhen has become a multi-nuclei city over the past 30 years (i.e. impossible to find a simple gradient across the city). A preliminary test of the effects of scale (i.e. the side length of the grid cell) was carried out with $300,600,900,1200,1500$ and $1800 \mathrm{~m}$. First, the conversion maps of urban land and forest were intersected with the grid cells of different sizes. Second, the proportions of the valid cells, which could be defined by whether there were conversions within this cell, were calculated at six different scales. Finally, the proportion change charts with the scale indicated that the cell size of $900 \mathrm{~m} \times 900 \mathrm{~m}$ was the most appropriate scale because it retained more details than the larger scales while not containing potential noise at smaller scales. Our test confirmed that the length of nearly $1000 \mathrm{~m}$ (or $500 \mathrm{~m}$ radius window) was one of the effective scales on detecting urban landscape patterns or change as the previous studies (Kong and Nakagoshi 2006, Wu et al. 2006, Kong et al. 2007).

The conversion maps were intersected with 569 grid cells (figure 1(a)). Cells adjacent to the border, with $<5 \%$ area belonging to the study area, were excluded. Using the 'overlay' and 'tabulate' of GIS tools on the conversion maps within each grid cell, the CI values of urban gain, forest loss or gain at each stages were calculated:

$$
\begin{gathered}
\mathrm{CI}_{\text {loss }(j)}=\frac{\operatorname{ACA}_{\operatorname{loss}(j)}}{\operatorname{TLA}_{j}} \times 100 \% \\
\mathrm{CI}_{\text {gain }(j)}=\frac{\operatorname{ACA}_{\text {gain }(j)}}{\operatorname{TLA}_{j}} \times 100 \%
\end{gathered}
$$

where $\mathrm{CI}_{\text {loss }(j)}$ and $\mathrm{CI}_{\text {gain(j) }}$ are the conversion intensity values within the cell $j$; $\mathrm{ACA}_{\text {loss }(j)}$ and $\mathrm{ACA}_{\text {gain(j) }}$ are the annual conversion areas within the cell $j$ calculated by equation (1) or equation (2); TLA $j$ is the total landscape area within cell $j$. (The cells located at the boundary have less TLA than those completely included within the study area.)

Natural breaks method based upon Jenks optimization is the most highly regarded technique for class delineation (Dent 1999) and is the default classification approach in 
commercial GIS packages such as ArcGIS. Consequently, the CI values were classified into four intensity classes (i.e. no conversion, low conversion, medium conversion and high conversion).

Functional zones not only reflect the expanding intensity of urban area with the switches both in land cover (from rural to urban) and land use (from low intensity to high intensity), but also demonstrate the transformation of regional ecological functions (Zhao et al. 2003). In this study, 10 functional zones were identified based on the land-cover map of 2005, topography and the administrative districts (table 2, figure $1(a))$.

\section{Results}

\subsection{Land cover and changes}

The area of urban land was low as 192.3 ha $(0.49 \%$ of the total study area) in 1973 and 310.9 ha $(0.79 \%)$ in 1979 . Although there was a slow increase up to 1979 , urban land covered $<1 \%$. At the same time, forest cover increased consistently from 7256.3 ha $(18.33 \%)$ to 8982.4 ha $(22.69 \%)$. By 1995 , urban land had increased to 10155.0 ha $(25.66 \%)$. However, this process included two stages based on the change of forest cover. From 1979 to 1986 , forest area declined dramatically from 8982.4 ha $(22.69 \%)$ to 5554.7 ha $(14.03 \%$ ), while there was a slight increase at the following stage (from $14.03 \%$ to $16.74 \%$ ). After 1995 , the change of urban land and forest covers seemed relatively steady. An interesting finding was that both of them declined from 1995 to 2000 and then increased from 2000 to 2005 together. In 2005, urban area reached 11 093.8 ha $(28.03 \%)$ while forest area restored to 7709.7 ha $(19.48 \%)$. At the end of the study period, urban land increased to 12989.8 ha $(32.82 \%)$ and forest cover changed to 6732.6 ha $(17.01 \%)$ (figure $3(a))$.

\subsection{Land conversion}

At the pre-urban stage, the annual area of urban gain was only 30.2 ha $(0.08 \%$ of the total study area), but at the following five stages it increased to 472.4 ha $(1.19 \%)$, 793.3 ha $(2.00 \%), 525.5$ ha $(1.33 \%), 924.1$ ha $(2.33 \%)$ and 1312.9 ha $(3.32 \%)$, respectively. Meanwhile, the annual forest gain at the first stage was 613.4 ha $(1.55 \%)$ but forest cover had a loss of 325.7 ha $(0.82 \%)$. At the second stage, forest gain dropped to the minimum $(0.40 \%)$, and in the meantime forest loss increased to the peak value $(1.63 \%)$. At the third stage, forest gain increased slightly (from $0.40 \%$ to $0.73 \%$ ) but the loss declined dramatically (from $1.63 \%$ to $0.43 \%$ ). At the fourth stage, forest gain remained at the similar level $(0.63 \%)$ while the loss had another increase (to $1.11 \%$ ). At the fifth stage, a much larger forest gain was detected at an annual rate of 612.2 ha $(1.55 \%)$ - restored to the level of the pre-urban stage. At the last stage, annual forest gain decreased to 324.7 ha $(0.82 \%)$ while forest loss increased to 645.9 ha $(1.63 \%)$ (figure $3(b)$ ). When examining the general trends of forest conversion over time, the fluctuations could be observed for their loss or gain. Especially, the ridges of forest gain appeared at the first, third and fifth stages, while the ones of forest loss happened at second, fourth and last stages.

According to the exploration on the source of forest gain or the sink of forest loss, the annual area of forest converted with non-vegetated area (i.e. urban land, bare land and water area) always seemed low, compared to the conversion with other vegetation types (i.e. grassland or shrubland). For example, through all the stages the annual loss 


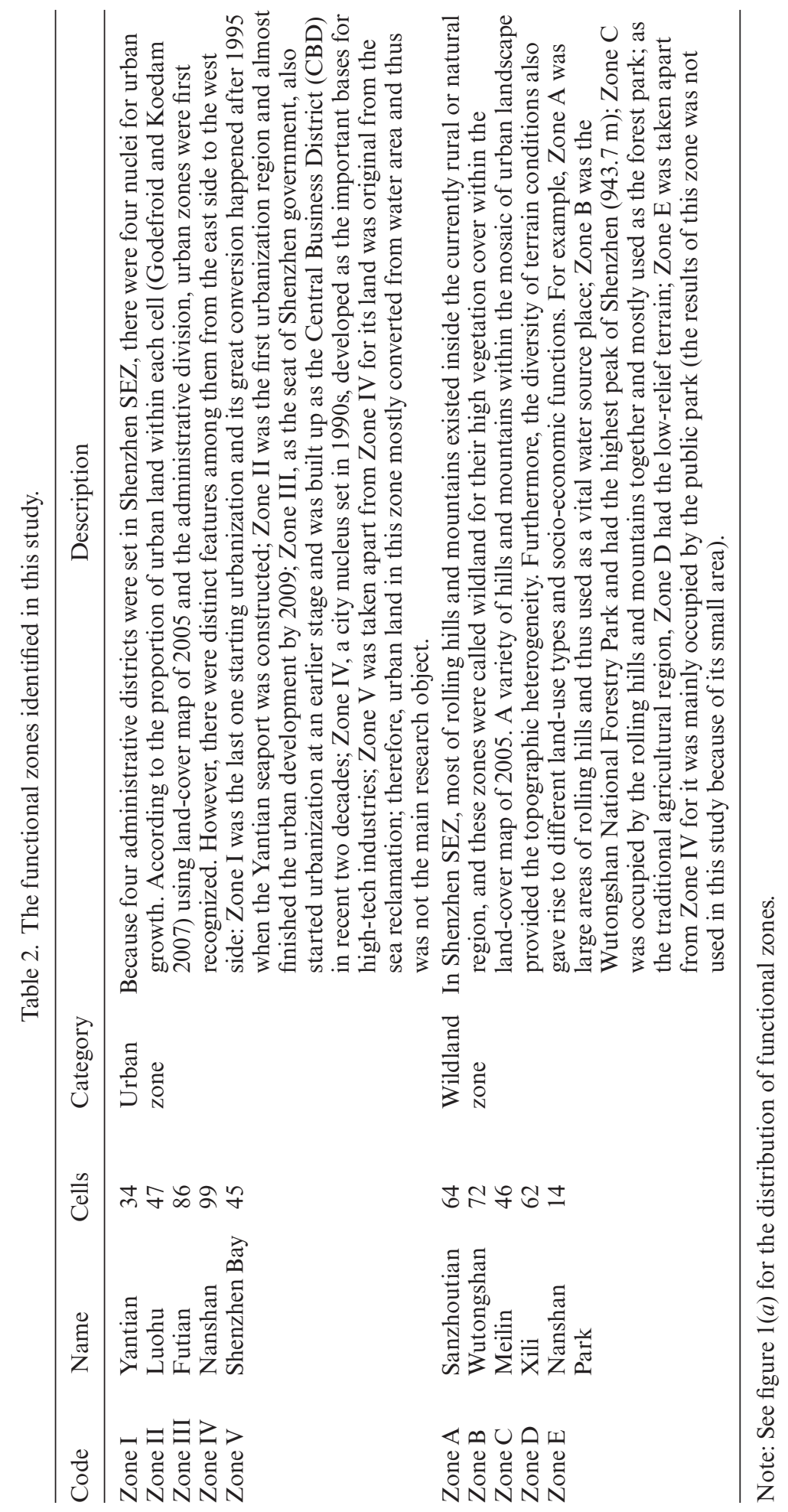


area to urban land was merely 0.02 ha $(<0.01 \%), 10.12$ ha $(0.03 \%), 6.65$ ha $(0.02 \%)$, 5.04 ha $(0.01 \%), 9.47$ ha $(0.02 \%)$ and 5.27 ha $(0.01 \%)$, respectively. Meanwhile, forest gain from urban land also had very low values, but experienced a slight increase trend (i.e. $0.00,0.00,0.64,2.52,5.67$ and 1.15 ha, respectively).

\subsection{Land conversion intensity by functional zones}

Urban CI values varied by time and space. In figure 4(a), all the CI values at the first stage within four urban zones approached 0. From 1979 to 1986, these values have an abrupt increase particularly within Zones II and III. Since then, there was a large difference in the change trends of CI values among different urban zones. For Zone I, the values had a steadily increased and accelerated trend as the urbanization process. Meanwhile, the opposite trend happened in Zone II, in which the CI values continued

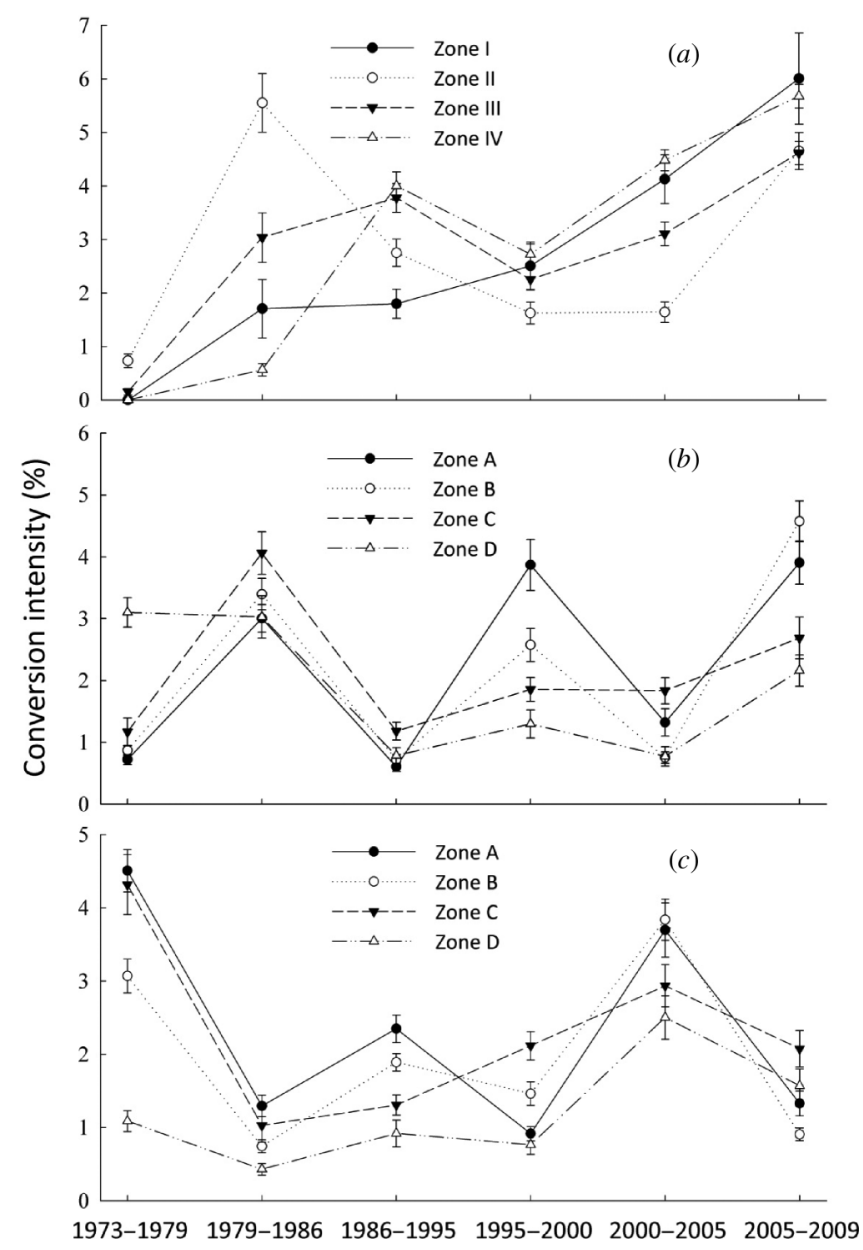

Figure 4. The changes of mean values (and standard error) of conversion intensity (CI) on urban gain $(a)$ within urban zones (Zones I, II, III and IV) and on forest loss $(b)$ or gain (c) within wildland zones (Zones A, B, C and D) through six urbanization stages.

Note: See table 2 and figure 1(a) for the functional zone-based CI analysis. 
Table 3. The percentage of grid cells on medium to high CI of UL and UF within urban zones.

\begin{tabular}{lcrrrr}
\hline Class & Stage & Zone I & Zone II & Zone III & Zone IV \\
\hline UL gain & $1973-1979$ & 0.0 & 25.6 & 4.7 & 0.0 \\
& $1979-1986$ & 20.6 & 74.5 & 39.5 & 8.1 \\
& $1986-1995$ & 32.4 & 61.7 & 69.8 & 69.7 \\
& $1995-2000$ & 50.0 & 36.2 & 53.5 & 67.7 \\
& $2000-2005$ & 76.5 & 21.3 & 61.6 & 86.9 \\
UF loss & $2005-2009$ & 67.7 & 6.4 & 3.5 & 12.1 \\
& $1973-1979$ & 2.9 & 0.0 & 3.5 & 16.2 \\
& $1979-1986$ & 26.5 & 12.8 & 5.8 & 2.0 \\
& $1986-1995$ & 44.1 & 4.3 & 3.5 & 2.0 \\
& $1995-2000$ & 14.7 & 4.3 & 2.3 & 1.0 \\
& $2000-2005$ & 8.8 & 0.0 & 1.2 & 3.0 \\
UF gain & $2005-2009$ & 14.7 & 10.6 & 2.3 & 1.0 \\
& $1973-1979$ & 23.5 & 14.9 & 5.8 & 0.0 \\
& $1979-1986$ & 23.5 & 2.1 & 5.8 & 0.0 \\
& $1986-1995$ & 5.9 & 4.3 & 1.2 & 1.0 \\
& $1995-2000$ & 2.9 & 0.0 & 3.5 & 3.0 \\
& $2000-2005$ & 2.9 & 8.5 & 4.7 & 5.1 \\
& $2005-2009$ & 2.9 & 8.5 & 20.9 & 5.1 \\
\hline
\end{tabular}

Notes: CI, conversion intensity; UL, urban land; UF, urban forest.

See table 2 and figure 1 $(a)$ for the functional zone-based CI analysis.

to decline until the fourth stage and then had a big increase at the sixth stage. Zones III and IV experienced the similar urbanization process, which was not monotonic increase as Zone I but had two peaks at the third and last stages.

The medium or high intensity of urban gain at the pre-urban stage (i.e. 1973-1979) mainly appeared in Zones II and III (figure 5), with more in Zone II than in Zone III (i.e. the urban sprawl mainly started in Zone II). At the second stage, these conversions within Zones II and III increased. Moreover, they also happened in other urban zones. At the third stage, Zones III and IV began to experience intense conversions, while the high conversions in Zone II started to decline. Since then, the medium and high conversions in Zone I steadily increased until the end of the study period. During the fourth and fifth stages, the medium conversions of Zone II and the high conversions of Zones III and IV dropped down. However, medium conversions in Zones III and IV continued to increase until the last stage.

According to the percentages of cells with medium to high CI values in table 3 , the distinct change trends of urban CI values among city nuclei could be further revealed. In the eastern part of Shenzhen, the percentages in Zone I had a steady increase while they decreased consistently in Zone II. In the west, Zones III and IV showed the similar fluctuations in the percentages. Furthermore, the percentages in Zone III were much higher than that in Zone IV at the early stages, but lower at the later stages.

Forest conversions rarely happened within urban zones but mostly within wildland zones (figure 5). Among the urban zones, the percentages of cells with medium to high conversions showed similar change trends for Zones II, III and IV (table 3). For example, the crests of forest loss appeared at the second stage. After that, the percentages declined gradually. For forest gain, the medium to high conversions had an obvious increase as the city development. Compared to other urban zones, the urbanization in Zone I started relatively late (figure 6). Correspondingly, the crest of forest loss 

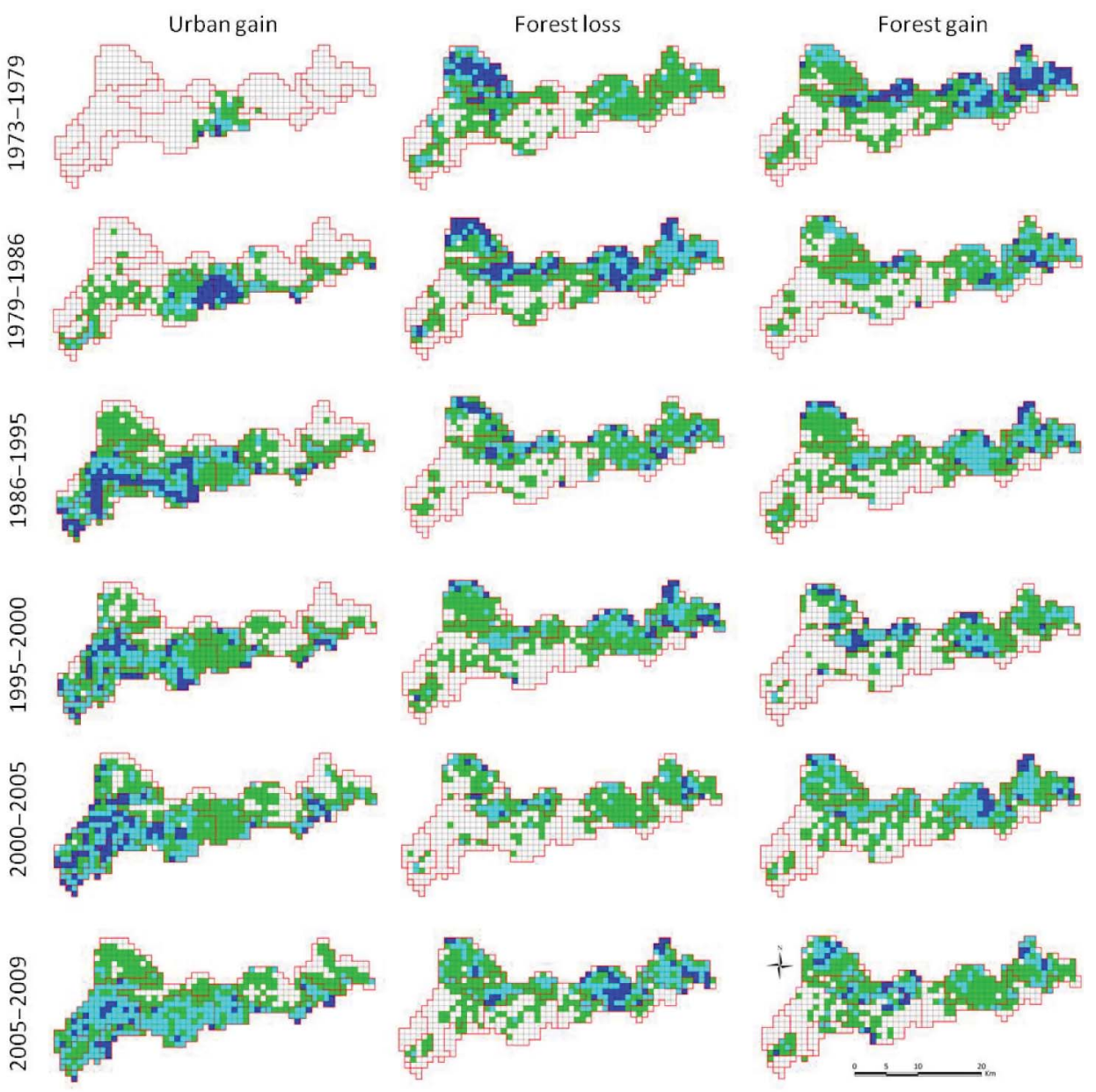

$\begin{array}{ll}\square \text { No conversion }(\mathrm{Cl}=0) & \text { Medium conversion (medium } \mathrm{Cl} \text { ) } \\ \text { Low conversion (low Cl) } & \text { High conversion (high } \mathrm{Cl} \text { ) }\end{array}$

Figure 5. The changes of four classes of conversion intensity (CI) values on urban gain, forest loss or gain through six urbanization stages.

Note: CI values were produced by equation (3) or equation (4) and then classified by the natural break algorithm; the percentages of cells with medium to high CI values are shown in table 3 ; see figure $1(a)$ and table 2 for the descriptions of functional zones.

appeared relatively late (i.e. at the third stage) and the medium to high conversions for forest gain still remained at a low level until the end of this study.

Zones $\mathrm{A}$ and $\mathrm{B}$, as the wildland zones in the eastern region, presented similar fluctuation trends on the forest CI values (figure $4(b)$ and $(c)$ ). Meanwhile, their percentages of cells with medium to high conversions also confirmed the fluctuation trends (table 4). Particularly, three crests of forest loss appeared at the second, fourth and last stages, while the gain crests were observed at the first, third and fifth stages. In the western part, Zones $\mathrm{C}$ and $\mathrm{D}$ also displayed the similar change trends on the forest CI values (figure $4(b)$ and $(c)$ ). Generally, at the second stage there were the maximum values on forest loss and minimum ones on forest gain through all 


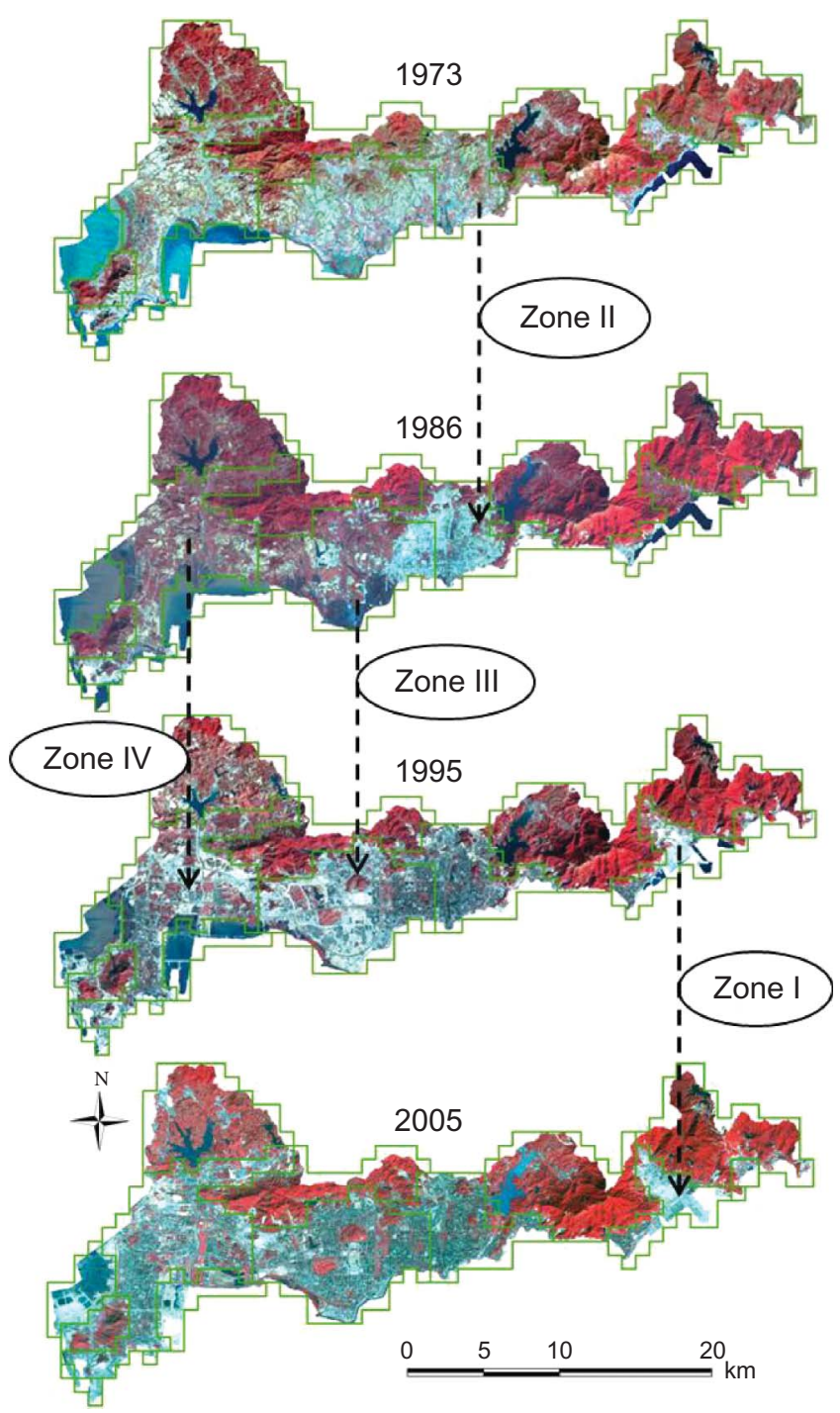

Figure 6. The typical sprawl of urban land within four urban zones (i.e. Zones I, II, III and IV) shown by four historical false colour composite images. Note the sequence of urban sprawl among urban zones.

Note: The descriptions of these functional zones are listed in figure 1(a) and table 2.

the stages. After that, the CI values on forest loss dramatically declined and then remained at a moderate rate while the ones on forest gain gradually increased until the fifth stage. However, their medium to high conversions indicated different trends (table 4). For example, the fluctuation trend was also observed in Zone $\mathrm{C}$ although the crests emerged at different stages compared with the ones of Zones A and B. Specifically, the loss crests arose at the second and fifth stages, while the gain crests came forth at the first and fourth stages. Unlike Zone C, the change trends of medium to high conversions in Zone D presented as the nearly linear change through the whole urbanization process. 
Table 4. The percentage of grid cells on medium to high CI of UF within wildland zones.

\begin{tabular}{lccccc}
\hline Class & Stage & Zone A & Zone B & Zone C & Zone D \\
\hline UF loss & $1973-1979$ & 12.5 & 22.2 & 28.3 & 82.3 \\
& $1979-1986$ & 81.3 & 75.0 & 80.4 & 56.5 \\
& $1986-1995$ & 31.3 & 34.7 & 67.4 & 32.3 \\
& $1995-2000$ & 67.2 & 51.4 & 47.8 & 22.6 \\
& $2000-2005$ & 26.6 & 15.3 & 52.2 & 17.7 \\
\multirow{4}{*}{ UF gain } & $2005-2009$ & 73.4 & 76.4 & 50.0 & 37.1 \\
& $1973-1979$ & 89.1 & 72.2 & 78.3 & 29.0 \\
& $1979-1986$ & 59.4 & 37.5 & 41.3 & 19.4 \\
& $1986-1995$ & 73.4 & 65.3 & 45.7 & 22.6 \\
& $1995-2000$ & 31.3 & 45.8 & 76.1 & 27.4 \\
& $2000-2005$ & 62.5 & 75.0 & 60.9 & 45.2 \\
& $2005-2009$ & 40.6 & 22.2 & 58.7 & 45.2 \\
\hline
\end{tabular}

Notes: CI, conversion intensity; UF, urban forest.

See table 2 and figure $1(a)$ for the functional zone-based CI analysis.

\section{Discussion}

\subsection{Nonlinear change of urban forest cover over time}

As a result of complex interactions among environmental, social, political and historical factors, a variety of driving forces could impact land cover and further interact dynamically to produce different sequences and trajectories (Nagendra et al. 2004). Before 1979, for its neighbouring with capitalist Hong Kong and the strict 'seclusion policy' adopted by mainland China, Shenzhen was a poor town with a small population. At that time, it belonged to the agriculture age while land cover was characterized by natural, semi-natural or agricultural types (figure 6). Therefore, at the first (i.e. pre-urban) stage, there was a slow development of urban land but a dramatic increase in forest cover due to the natural vegetation growth. At this stage, forest loss could be attributed to the natural factors (e.g. fire, disease, pest) and human demands on food or firewood.

In 1979, Shenzhen SEZ was founded and thus urbanization was launched. As a result, urban land abruptly increased at the cost of converting from other types. To satisfy the immediate demands of human, land conversion from one type to another and land-cover modification by anthropogenic management largely changed much of the earth's surface (Meyer and Turner 1992, Vitousek et al. 1997). Usually, the forests were the largest source for development use (Alig et al. 2004) and forest cover consequently decreased obviously at the initial stage of urbanization.

The gains of urban area were considered predominantly from the conversion of croplands or forests (Thomlinson and Rivera 2000, Alig et al. 2004, Helmer 2004, Kong and Nakagoshi 2006, Boentje and Blinnikov 2007, Kromroy et al. 2007, Lathrop et al. 2007). Whereas, according to our study on conversion sink of forest loss, the cost of urban growth in Shenzhen was not directly from forests. In fact, forest losses in the study area were the conversions to grassland or shrubland, which revealed that the city growth grasped massive timber or fuel from the local forests at the initial stage of urbanization.

After 1986, although urban growth continued even with slight accelerations, forest losses declined dramatically and their gains had a few increase at the following stages. 
This was probably because the accessible forests reduced and the need for timber or fuels from local forest consequently decreased (Ode and Fry 2006, De Clercq et al. 2007). Another reason was that the remnant forests became protected by the local government. For instance, the government adopted a new forest policy in 1998, almost 20 years after the reform and openness of mainland China, entitled 'the Natural Forest Conservation Program', to raise forest cover and increase their productivity (Zhang et al. 2000).

As the development of urban structure and socio-economic composition, the change of urban landscape became more sophisticated and undoubtedly influenced by anthropogenic factors. For example, after 2003, many cities of China are experiencing the real estate craze. Shenzhen as one of the top cities in China is leading the booming market in the urban land transformation and real estate development. Similarly, a subtle decline trend on urban land from 1995 to 2000 was also constrained by variety of natural and societal factors (e.g. land, population and environmental capabilities; financial crisis in Asia in 1997). Furthermore, in recent years aimed for an ecological and greening city, some urban land was converted to other types due to the urban reorganization and reconstruction. For example, many impervious public squares were replaced by lawns and green belts. Additionally, various types of urban afforestation and greening were carried out according to the policy adjustment of local government (Zhang et al. 2000). Therefore, human activities and other natural factors promoted the nonlinear change process on urban land or forest coverage.

On the whole, as the city development of Shenzhen, especially after 2000, forest cover has been restored to the level of pre-urban stage. First, this was because of the resilience and regeneration ability of natural vegetation within the wildland zones. More importantly, transformations of public policy and society demands brought about the restoration. In recent years, as the urban pollution intensified, city residents inhabiting the developed cities of China like Shenzhen have promoted environmental awareness and preferred the ecological functions and services of forests to their products. In fact, people living in rich world could find the substitutes of forest products (e.g. using fossil fuel instead of firewood) or import these products from rural area but realized it is impossible to obtain the substitutes or importation of these services. Therefore, these demands pushed the local government into adjusting policy and investing more financial resource on the urban forest management and construction.

\subsection{Spatial heterogeneity of forest conversion by functional zones}

Large cities in China, such as Beijing, Nanjing, Guangzhou and Shanghai, have changed from concentric cities to multi-nuclei ones (Wu et al. 2006, Zhu et al. 2006, $\mathrm{Xu}$ et al. 2007, Yu and Ng 2007). As a young megacity in China, Shenzhen also experienced the similar changes (figure 6), which included the development from a single nucleus located at Zone II within Luohu District to the multi-nuclei of Zones I, II, III and IV distributed within four districts (i.e. Luohu, Futian, Nanshan and Yantian). The land-cover pattern of urban area could reflect the range, intensity and frequency of underlying human intervention (Redman 1999). Due to the difference of starting time, range, intensity and frequency of conversions on urban land among these nuclei, the urbanization within Zones I, II, III and IV displayed as a non-synchronizing process (figure 6). Furthermore, such processes resulted in a variety of infrastructural and socio-economic factors within these zones (e.g. the urban form; 
built infrastructure and location; and the consumption preferences of heterogeneous households and businesses) (Liu et al. 2007).

Although previous studies have found that urban growth exhibited the characteristics of spatial dependency among different parts of the region (Weng 2002), our study further witnessed that urban sprawl could cause the spatial heterogeneity of forest conversions outside or inside the city. Concretely, the changes of forest CI within each wildland zone (i.e. Zones A, B, C and D) depended on the variation of urban CI within the adjacent urban zones (i.e. Zones I, II, III and IV). For example, it could be examined by exploring the concurrent change trends between urban conversions (e.g. Zones I and II) and forest conversions (e.g. Zones A and B) as follows. First, due to its geographical advantage of connecting Hong Kong by landway, the Luohu District (Zone II) was the earliest urbanizated zone with the urban development almost finished by 2009. Second, as the Yantian seaport was constructed in the 1990s, the Yantian District (Zone I) became the last zone starting the urbanization and was still experiencing the consistent urban sprawl at the last stage. Subsequently, urban conversions within Zones I and II presented the opposite trends, which were the linear decline for Zone II and linear increase for Zone I. Consequently, the intermixing urbanization processes of Zones I and II in the eastern part of Shenzhen caused the fluctuating trends of forest conversion within their neighbouring Zones A and B (table 4). For the same reason, forest CI within these two urban zones showed the different change trends, especially presenting as the opposite ones on the CI of forest gains (table 3).

Spatial heterogeneity of forest conversion was not only caused by the range or intensity of urbanization, but also seemed dependent on the distinct land-use types principally determined by the terrain conditions (figure 7). Although land cover refers to the biophysical earth surface, land use is controlled by human, socio-economic and political influences on the land (Geist and Lambin 2002). For example, the plain land in Shenzhen was used to develop built infrastructure, while the forests mainly distributed over the rolling hills and mountains (figure $7(e)$ ). Therefore, the medium to high intensities of forest conversions happened primarily within wildland zones (i.e. Zones A, B, C and D). Furthermore, a variety of terrain factors, including the accessibility of forest for residents or peasants, determined the land-use types of these hills and mountains (e.g. forest park, water source place and agricultural land). From figure 7, we could observe that the low hills (figure $7(d)$ ) and the mountainsides of low elevation (figure 7(c)), all of which are basically below $235 \mathrm{~m}$, have been developed for the orchards or other agricultural land. Consequently, the forests usually inhabited the continuous mountains (e.g. Sanzhoutian in Zone A, figure 7(a); and Wutongshan in Zone B, figure $7(b)$ ) or remained over the mountainous area at an altitude over approximately $250 \mathrm{~m}$ (e.g. Tanglangshan in Zone C, figure 7(c)). Therefore, the medium to high intensities of Zone $\mathrm{C}$ indicated the similar rule to the Zones $\mathrm{A}$ and B (table 4), which was the forest gain or loss displayed the fluctuating trend as the urban conversion changes of its neighbouring urban zone (i.e. Zone III). Meanwhile, due to the featured land-use types, forest conversions within Zone D showed a linear change trend, which included a consistent increase for forest gain and a nearly linear decline for the loss.

\section{Conclusions}

Urban forest cover was generally assumed to decrease linearly and inversely to urban land regardless of spatial and temporal drivers, while we found that this was not 


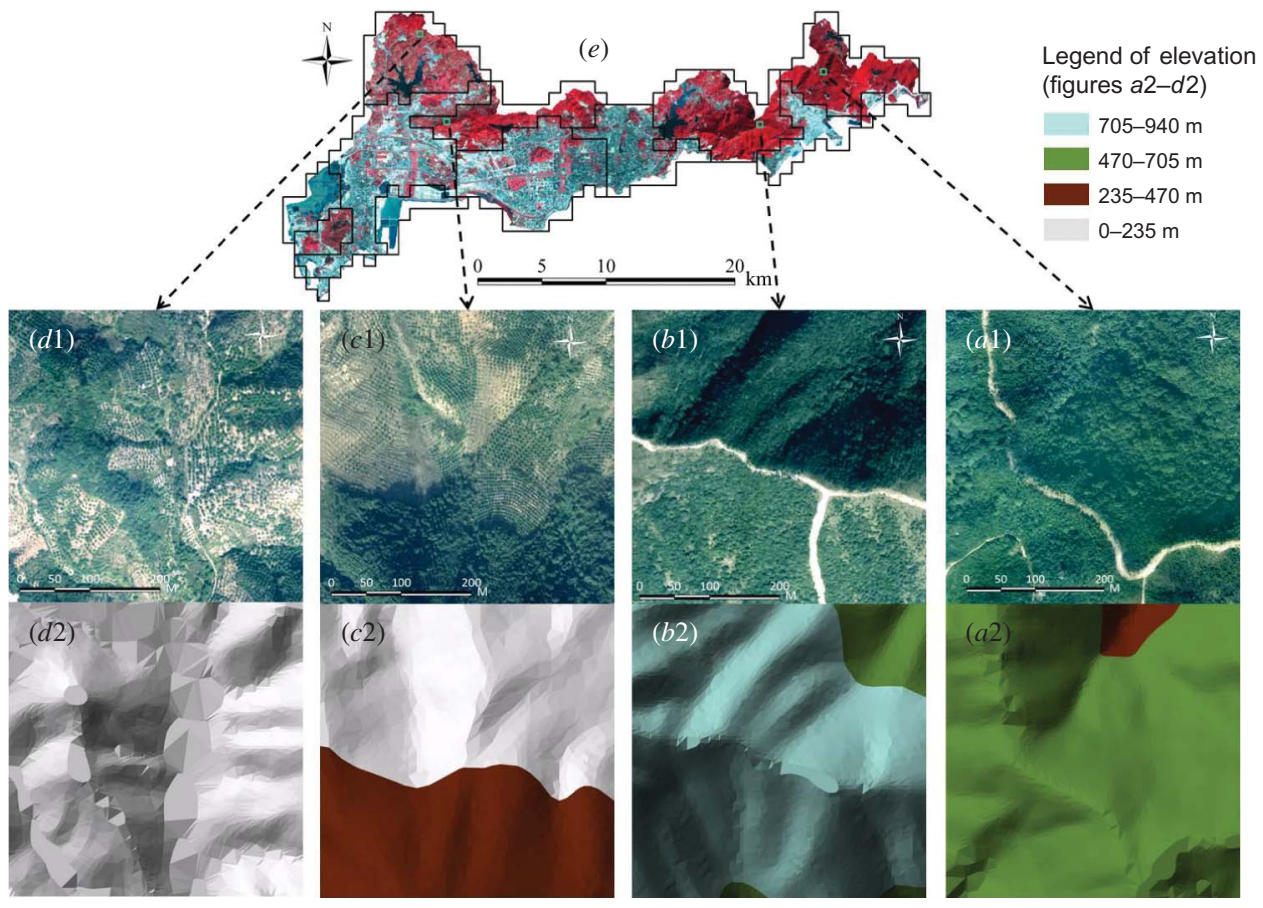

Figure 7. The examples show the distribution of urban forest influenced by terrain conditions and corresponding land-use types within four wildland zones (Zones A, B, C and D) using colour aerial photographs of 2001 with $0.6 \mathrm{~m}$ resolution $(a 1, b 1, c 1$ and $d 1)$, topographic maps in Triangulated Irregular Network (TIN) $(a 2, b 2, c 2$ and $d 2)$ and the Landsat false colour composite image of $2000(e)$.

always the case. In fact, forest cover and conversions in Shenzhen SEZ presented the nonlinear dynamic changes over time with the development of the city and the transformations of underlying human demands and government's policy. Meanwhile, forest conversions in space showed large spatial variation caused by the mass discrepancy of urbanization range or intensity among different urban zones and also related to both the geographical settings and the socio-economic zonings of the land use. Our results supported the initial hypothesis and provided an advanced comprehension of the spatiotemporal characteristics of urban forest changes through a model urban sprawl.

In the foreseeable future, urbanization will continue to be one of the major global environmental changes; therefore, characterizing and understanding the changes of urban forests should be critical (Seto and Fragkias 2005). Considering the challenge of diminishing the negative impacts of urbanization while keeping its economic and social benefits (Foley et al. 2005), more studies on urban forests by remote sensing and GIS approach should be applied in the future. In this study, we demonstrate conclusively that historical remote sensing images are reliable data source, which could objectively and authentically record what has happened on the Earth's surface in the past. The scientific analysis based on GIS and other appropriate statistical tools will contribute effectively to reasonable policy and suitable planning, which could help to preserve and even improve the remnant forests inside and around the cities, with the ultimate goal for urban ecosystem health and sustainable development. In sum, the 
remote sensing method of exploring historical land-cover changes and land conversion detection paralleling a functional zone-based grid cellular analysis seems sufficiently robust and can be applied in other urban areas.

\section{Acknowledgements}

We thank Nan Lu, Haiqiang Guo, Burkhard Wilske, Ranjeet John, Jessica Schaefer and Jianye $\mathrm{Xu}$ in the LEES Laboratory at the University of Toledo; Luo Guo, Yantun Song, Zhi Chen and Jie Wu in the 3S Laboratory of Sun Yat-sen University; Nan Li from Fairylake Botanical Garden of Shenzhen; and the anonymous reviewers for their help in the research or their constructive suggestions on revising the earlier manuscript. We also thank Dr. Luo Guo for providing some remote sensing data. This study was supported by the City Management Department of Shenzhen, the ZhangHongda Science Foundation of Sun Yat-sen University, the University of Toledo and the China Scholarship Council.

\section{References}

Alig, R.J., Kline, J.D. and Lichtenstein, M., 2004, Urbanization on the US landscape: looking ahead in the 21st century. Landscape and Urban Planning, 69, pp. 219-234.

Attwell, K., 2000, Urban land resources and urban planting - case studies from Denmark. Landscape and Urban Planning, 52, pp. 145-163.

Boentje, J.P. and Blinnikov, M.S., 2007, Post-Soviet forest fragmentation and loss in the Green Belt around Moscow, Russia (1991-2001): a remote sensing perspective. Landscape and Urban Planning, 82, pp. 208-221.

Congalton, R.G., 1991, A review of accessing the accuracy of classification of remotely sensed data. Remote Sensing of Environment, 37, pp. 35-46.

Conine, A., Xiang, W.N., Young, J. and Whitley, D., 2004, Planning for multipurpose greenways in Concord, North Carolina. Landscape and Urban Planning, 68, pp. 271-287.

De Clercq, E.M., De Wulf, R. and van Herzele, A., 2007, Relating spatial pattern of forest cover to accessibility. Landscape and Urban Planning, 80, pp. 14-22.

Dent, B.D., 1999, Cartography: Thematic Map Design, 5th ed., pp. 147-149 (New York: WCB/McGraw-Hill).

Dwyer, J.F., Mcpherson, E.G., Schroeder, H.W. and Rowntree, R.A., 1992, Assessing the benefits and costs of the urban forest. Journal of Arboriculture, 18, pp. 227-234.

ERDAS, 2003, ERDAS Field Guide, 7th ed., pp. 255-258 (Atlanta, GA: Leica Geosystems GIS and Mapping, LLC).

Foley, J.A., Defries, R., Asner, G.P., Barford, C., Bonan, G., Carpenter, S.R., Chapin, F.S., Coe, M.T., Daily, G.C., Gibbs, H.K., Helkowski, J.H., Holloway, T., Howard, E.A., Kucharik, C.J., Monfreda, C., Patz, J.A., Prentice, I.C., Ramankutty, N. and SNYder, P.K., 2005, Global consequences of land use. Science, 309, pp. 570-574.

Geist, H.J. and Lambin, E.F., 2002, Proximate causes and underlying driving forces of tropical deforestation. Bioscience, 52, pp. 143-150.

Geoghegan, J., 2002, The value of open spaces in residential land use. Land Use Policy, 19, pp. 91-98.

Gobster, P.H. and Westphal, L.M., 2004, The human dimensions of urban greenways: planning for recreation and related experiences. Landscape and Urban Planning, 68, pp. $147-165$.

Godefroid, S. and Koedam, N., 2007, Urban plant species patterns are highly driven by density and function of built-up areas. Landscape Ecology, 22, pp. 1227-1239. 
Grimm, N.B., Faeth, S.H., Golubiewski, N.E., Redman, C.L., Wu, J.G., Bai, X.M. and Briggs, J.M., 2008, Global change and the ecology of cities. Science, 319, pp. 756-760.

Helmer, E.H., 2004, Forest conservation and land development in Puerto Rico. Landscape Ecology, 19, pp. 29-40.

Hu, Z.Y., 2007, Using NDVI differencing and temporal logic to enhance ISODATA classification in urban environments. GIScience \& Remote Sensing, 44, pp. 48-67.

JiM, C.Y. and CHEN, S.S., 2003, Comprehensive greenspace planning based on landscape ecology principles in compact Nanjing city, China. Landscape and Urban Planning, 65 , pp. $95-116$.

Kaufmann, R.K. and Seto, K.C., 2001, Change detection, accuracy, and bias in a sequential analysis of Landsat imagery in the Pearl River delta, China: econometric techniques. Agriculture Ecosystems and Environment, 85, pp. 95-105.

Kong, F.H. and Nakagoshi, N., 2006, Spatial-temporal gradient analysis of urban green spaces in Jinan, China. Landscape and Urban Planning, 78, pp. 147-164.

Kong, F.H., Yin, H.W. and NAKagoshi, N., 2007, Using GIS and landscape metrics in the hedonic price modeling of the amenity value of urban green space: a case study in Jinan City, China. Landscape and Urban Planning, 79, pp. 240-252.

Kromroy, K., Ward, K., Castillo, P. and Juzwik, J., 2007, Relationships between urbanization and the oak resource of the Minneapolis/St. Paul Metropolitan area from 1991 to 1998. Landscape and Urban Planning, 80, pp. 375-385.

KUPFER, J., 2006, National assessments of forest fragmentation in the US. Global Environmental Change, 16, pp. 73-82.

Lathrop, R.G., Tulloch, D.L. and Hatfield, C., 2007, Consequences of land use change in the New York-New Jersey Highlands, USA: landscape indicators of forest and watershed integrity. Landscape and Urban Planning, 79, pp. 150-159.

Liu, J.G., Dietz, T., Carpenter, S.R., Alberti, M., Folke, C., Moran, E., Pell, A.N., Deadman, P., Kratz, T., Lubchenco, J., Ostrom, E., Ouyang, Z., Provencher, W., Redman, C.L., Schneider, S.H. and Taylor, W.W., 2007, Complexity of coupled human and natural systems. Science, 317, pp. 1513-1516.

Macdonald, K. and Rudel, T.K., 2005, Sprawl and forest cover: What is the relationship? Applied Geography, 25, pp. 67-79.

Madhavan, B.B., Kubo, S., Kurisaki, N. and Sivakumar, T.V.L.N., 2001, Appraising the anatomy and spatial growth of the Bangkok Metropolitan area using a vegetationimpervious-soil model through remote sensing. International Journal of Remote Sensing, 22, pp. 789-806.

Mcdonnell, M.J. and Pickett, S.T.A., 1990, Ecosystem structure and function along urban-rural gradients: an unexploited opportunity for ecology. Ecology, 71, pp. $1232-1237$.

Meyer, W.B. and Turner, B.L., 1992, Human-population growth and global land-use cover change. Annual Review of Ecology and Systematics, 23, pp. 39-61.

Nagendra, H., Munroe, D.K. and Southworth, J., 2004, From pattern to process: landscape fragmentation and the analysis of land use/land cover change. Agriculture Ecosystems and Environment, 101, pp. 111-115.

Ode, A. and Fry, G., 2006, A model for quantifying and predicting urban pressure on woodland. Landscape and Urban Planning, 77, pp. 17-27.

Phinn, S., Stanford, M., Scarth, P., Murray, A.T. and Shyy, P.T., 2002, Monitoring the composition of urban environments based on the vegetation-impervious surface-soil (VIS) model by subpixel analysis techniques. International Journal of Remote Sensing, 23, pp. 4131-4153.

Pickett, S.T.A., Cadenasso, M.L., Grove, J.M., Nilon, C.H., Pouyat, R.V., Zipperer, W.C. and CostanZA, R., 2001, Urban ecological systems: linking terrestrial ecological, physical, and socioeconomic components of metropolitan areas. Annual Review of Ecology and Systematics, 32, pp. 127-157. 
Redman, C.L., 1999, Human dimensions of ecosystem studies. Ecosystems, 2, pp. 296-298.

RIDD, M.K., 1995, Exploring a V-I-S (vegetation-impervious-soil) model for urban ecosystem analysis through remote sensing: comparative anatomy for cities. International Journal of Remote Sensing, 16, pp. 2165-2185.

RidD, M.K. and LiU, J.J., 1998, A comparison of four algorithms for change detection in an urban environment. Remote Sensing of Environment, 63, pp. 95-100.

Schweitzer, F., 2006, Cities and complexity: understanding cities with cellular automata, agent-based models, and fractals. Nature, 441, p. 815.

Seto, K.C. and Fragkias, M., 2005, Quantifying spatiotemporal patterns of urban land-use change in four cities of China with time series landscape metrics. Landscape Ecology, 20, pp. 871-888.

Seto, K.C., Kaufmann, R.K. and Woodcock, C.E., 2000, Landsat reveals China's farmland reserves, but they're vanishing fast. Nature, 406, p. 121.

Seto, K.C., Woodcock, C.E., Song, C., Huang, X., Lu, J. and Kaufmann, R.K., 2002, Monitoring land-use change in the Pearl River delta using Landsat TM. International Journal of Remote Sensing, 23, pp. 1985-2004.

Shenzhen Statistical Bureau, 2006, Shenzhen Statistical Yearbook (Shenzhen: Shenzhen Statistical Press) [in Chinese].

Stow, D., Coulter, L., Kaiser, J., Hope, A., Service, D., Schutte, K. and Walters, A., 2003, Irrigated vegetating assessments for urban environments. Photogrammetric engineering and Remote Sensing, 69, pp. 381-390.

Thomlinson, J.R. and Rivera, L.Y., 2000, Suburban growth in Luquillo, Puerto Rico: some consequences of development on natural and semi-natural systems. Landscape and Urban Planning, 49, pp. 15-23.

United Nations, 2002, World Urbanization Prospects: The 2001 Revision (New York: United Nations Population Division).

United Nations, 2006, World Urbanization Prospects: The 2005 Revision (New York: United Nations Population Division).

Vitousek, P.M., Mooney, H.A., Lubchenco, J. and Melillo, J.M., 1997, Human domination of Earth's ecosystems. Science, 277, pp. 494-499.

WENG, Q., 2001, A remote sensing-GIS evaluation of urban expansion and its impact on surface temperature in the Zhujiang delta, China. International Journal of Remote Sensing, 22, pp. 1999-2014.

WENG, Q.H., 2002, Land use change analysis in the Zhujiang delta of China using satellite remote sensing, GIS and stochastic modelling. Journal of Environmental Management, 64, pp. 273-284.

WENG, Y.C., 2007, Spatiotemporal changes of landscape pattern in response to urbanization. Landscape and Urban Planning, 81, pp. 341-353.

Wu, Q., Hu, D., WANG, R.S., Li, H.Q., He, Y., WANG, M. and WANG, B.H., 2006, A GIS-based moving window analysis of landscape pattern in the Beijing metropolitan area, China. International Journal of Sustainable Development and World Ecology, 13, pp. 419-434.

XIE, Y.C., SHA, Z.Y. and BAI, Y.F., 2010, Classifying historical remotely sensed imagery using a tempo-spatial feature evolution (T-SFE) model. ISPRS Journal of Photogrammetry and Remote Sensing, 65, pp. 182-190.

Xu, C., Liu, M.S., Zhang, C., An, S.Q., Yu, W. and Chen, J.M., 2007, The spatiotemporal dynamics of rapid urban growth in the Nanjing metropolitan region of China. Landscape Ecology, 22, pp. 925-937.

YANG, X.J., 2002, Satellite monitoring of urban spatial growth in the Atlanta metropolitan area. Photogrammetric Engineering and Remote Sensing, 68, pp. 725-734.

YU, X.J. and $\mathrm{NG}_{\mathrm{G}}$ C.N., 2007, Spatial and temporal dynamics of urban sprawl along two urbanrural transects: a case study of Guangzhou, China. Landscape and Urban Planning, 79, pp. $96-109$. 
YuAN, F. and BAUER, M.E., 2007, Comparison of impervious surface area and normalized difference vegetation index as indicators of surface urban heat island effects in Landsat imagery. Remote Sensing of Environment, 106, pp. 375-386.

Zhang, P.C., Shao, G.F., Zhao, G., Le Master, D.C., Parker, G.R., Dunning, J.B. and LI, Q.L., 2000, Ecology - China's forest policy for the 21st century. Science, 288, pp. 2135-2136.

Zhao, B., Nakagoshi, N., Chen, J.K. and Kong, L.Y., 2003, The impact of Urban Planning on land use and land cover in Pudong of Shanghai, China. Journal of Environmental Sciences-China, 15, pp. 205-214.

Zhu, M., Xu, J.G., JiAnG, N., LI, J.L. and FAN, Y.M., 2006, Impacts of road corridors on urban landscape pattern: a gradient analysis with changing grain size in Shanghai, China. Landscape Ecology, 21, pp. 723-734. 